\title{
Erratum to: Efficacy and safety of fermented garlic extract on hepatic function in adults with elevated serum gamma-glutamyl transpeptidase levels: a double-blind, randomized, placebo-controlled trial
}

\author{
Ha-Na Kim ${ }^{1}$ - Sung-Goo Kang ${ }^{1}$ Yong Kyun Roh $^{2} \cdot$ Min-Kyu Choi ${ }^{2}$. \\ Sang-Wook Song ${ }^{1}$
}

Published online: 11 January 2017

(C) Springer-Verlag Berlin Heidelberg 2017

\section{Erratum to: Eur J Nutr \\ DOI 10.1007/s00394-016-1318-6}

In the original publication of the article, in the subsection "Preparation FGEs", sentences 3 and 5 have been published incorrectly. The sentence 3 should be "The sachets containing FGEs or placebo used in this study were produced by SK Bioland, Ltd., South Korea" and the sentence 5 should be "The solution was cooled at $37{ }^{\circ} \mathrm{C}$ and fermented with L. plantarum BL2 $(2 \% \mathrm{w} / \mathrm{w})$ in a fermenter for $36 \mathrm{~h}$. After the cultivation, the solutions were sterilized for $30 \mathrm{~min}$ at $121^{\circ} \mathrm{C}$, cooled at $50{ }^{\circ} \mathrm{C}$ ".

The original text has been updated accordingly.

The online version of the original article can be found under doi:10.1007/s00394-016-1318-6.

Sang-Wook Song

sswkoj@unitel.co.kr

Ha-Na Kim

onef01@ catholic.ac.kr

Sung-Goo Kang

hippo94@ naver.com

Yong Kyun Roh

rohyk@hallym.ac.kr

Min-Kyu Choi

abbi21c@hotmail.com

1 Department of Family Medicine, St. Vincent's Hospital, College of Medicine, The Catholic University of Korea, Seoul, Republic of Korea

2 Department of Family Medicine, Kangnam Sacred Heart Hospital, College of Medicine, Hallym University, Seoul, Republic of Korea 